\title{
Article
}

\section{The Babytwins Study Sweden (BATSS): A Multi-Method Infant Twin Study of Genetic and Environmental Factors Influencing Infant Brain and Behavioral Development}

\author{
Terje Falck-Ytter ${ }^{1,2,3}$, Linnea Hamrefors ${ }^{1,2}$, Monica Siqueiros Sanches ${ }^{2,4}$, Ana Maria Portugal ${ }^{2}$, Mark Taylor $^{5}$, \\ Danyang Li ${ }^{2,6}$, Charlotte Viktorsson ${ }^{1}$, Irzam Hardiansyah², Lynnea Myers ${ }^{2,7,8}$, Lars Westberg ${ }^{9}$, Sven Bölte ${ }^{2,10,11}$, \\ Kristiina Tammimies ${ }^{2,6}$ and Angelica Ronald ${ }^{12}$ \\ ${ }^{1}$ Development and Neurodiversity Lab (DIVE), Department of Psychology, Uppsala University, Uppsala, Sweden, ${ }^{2}$ Center of Neurodevelopmental Disorders (KIND), \\ Centre for Psychiatry Research; Department of Women's and Children's Health, Karolinska Institutet and Stockholm Health Care Services, Stockholm, Sweden, \\ ${ }^{3}$ Swedish Collegium for Advanced Study (SCAS), Uppsala, Sweden, ${ }^{4}$ Center for Interdisciplinary Brain Sciences Research, Department of Psychiatry and \\ Behavioral Sciences, Stanford University, Stanford, CA, USA, ${ }^{5}$ Department of Medical Epidemiology \& Biostatistics, Karolinska Institutet, Stockholm, Sweden, \\ ${ }^{6}$ Astrid Lindgren Children's Hospital, Karolinska University Hospital, Stockholm, Sweden, ${ }^{7}$ Department of Nursing, Gustavus Adolphus College, St. Peter, \\ Minnesota, USA, ${ }^{8}$ Clinical Pediatrics, Department of Women's and Children's Health, Karolinska Institutet, Stockholm, Sweden, ${ }^{9}$ Department of Pharmacology, \\ Institute of Neuroscience and Physiology at the Sahlgrenska Academy, University of Gothenburg, Gothenburg, Sweden, ${ }^{10} \mathrm{Child}$ and Adolescent Psychiatry, \\ Stockholm Health Care Services, Stockholm, Sweden, ${ }^{11}$ Curtin Autism Research Group, Curtin School of Allied Health, Curtin University, Perth, Western Australia, \\ Australia and ${ }^{12}$ Department of Psychological Sciences, Birkbeck, University of London, London, UK
}

\begin{abstract}
Twin studies can help us understand the relative contributions of genes and environment to phenotypic trait variation, including attentional and brain activation measures. In terms of applying methodologies such as electroencephalography (EEG) and eye tracking, which are key methods in developmental neuroscience, infant twin studies are almost nonexistent. Here, we describe the Babytwins Study Sweden (BATSS), a multi-method longitudinal twin study of $177 \mathrm{MZ}$ and $134 \mathrm{DZ}$ twin pairs (i.e., 622 individual infants) covering the 5-36 month time period. The study includes EEG, eye tracking and genetics, together with more traditional measures based on in-person testing, direct observation and questionnaires. The results show that interest in participation in research among twin parents is high, despite the comprehensive protocol. DNA analysis from saliva samples was possible in virtually all participants, allowing for both zygosity confirmation and polygenic score analyses. Combining a longitudinal twin design with advanced technologies in developmental cognitive neuroscience and genomics, BATSS represents a new approach in infancy research, which we hope to have impact across multiple disciplines in the coming years.
\end{abstract}

Keywords: Eye tracking; electroencephalography (EEG); biomarker; genetic; polygenic risk score; behavior genetics

(Received 22 June 2021; accepted 5 August 2021; First Published online 15 September 2021)

In this article, we describe the multimodal longitudinal twin study BATSS (Babytwins Study Sweden). The study is based on the idea that combining the field of developmental cognitive neuroscience and twin research can advance knowledge about the origins of individual variation in brain and behavioral development in infancy. While there are existing studies using traditional psychological methods, such as questionnaires and direct observation of infant twins, there are no infant ( $<2$ years) twin studies using a full array of state-of-the-art, advanced methodologies from developmental cognitive neuroscience, such as eye tracking and

Author for correspondence: Terje Falck-Ytter, Email: terje.falck-ytter@psyk.uu.se Cite this article: Falck-Ytter T, Hamrefors L, Siqueiros Sanches M, Portugal AM, Taylor M, Li D, Viktorsson C, Hardiansyah I, Myers L, Westberg L, Bölte S, Tammimies K, and Ronald A. (2021) The Babytwins Study Sweden (BATSS): A MultiMethod Infant Twin Study of Genetic and Environmental Factors Influencing Infant Brain and Behavioral Development. Twin Research and Human Genetics 24: 217-227, https://doi.org/10.1017/thg.2021.34 electroencephalography (EEG). These approaches can reveal unique aspects of infant brain and behavioral development.

The study of individual differences continues apace within the field of developmental science. Partly, this is due to the recognized need to predict who is likely to experience certain later outcomes (e.g., disease or developmental difficulties). Key constructs such as equifinality, multifinality, developmental cascades/pathways and probabilistic epigenesis all relate to individual differences in development (Cicchetti \& Rogosch, 1996; Gottlieb, 2007; Waddington, 2014). In parallel with the theoretical developments, the gradual accumulation of reliable and valid psychological measures for infancy research has also contributed to the enhanced focus on individual differences in developmental science.

In older children and adults, twin studies have for decades been instrumental in our understanding of why people differ in their traits and disease and disorder outcomes (Polderman et al., 2015). By comparing the degree of similarity in MZ and DZ twins,

(c) The Author(s), 2021. Published by Cambridge University Press. This is an Open Access article, distributed under the terms of the Creative Commons Attribution-NonCommercialNoDerivatives licence (http://creativecommons.org/licenses/by-nc-nd/4.0/), which permits non-commercial re-use, distribution, and reproduction in any medium, provided the original work is unaltered and is properly cited. The written permission of Cambridge University Press must be obtained for commercial re-use or in order to create a derivative work. 
one can quantify the relative contribution of genetic and environmental influences to single phenotypes. Furthermore, the multivariate extension of twin analyses allow for an array of analyses that explore, for example, the degree to which the same genetic influences and the same environmental influences affect two or more phenotypes or explain patterns of stability and change of the same phenotype over development. Twin studies can also shine light on the 'heritability of the environment' (i.e., when aspects of one's environment are shaped by one's genetic predispositions). Specifically, environments that are unique to each child can be incorporated into the twin design, and thus the role of genetic and environmental influences on a putative environment, such as stressful life events, can be estimated (Shakoor et al., 2016).

In terms of the existing twin literature applying brain-based measures from developmental cognitive neuroscience, EEG studies of infant twins are nearly nonexistent. EEG measures electrical activity arising from synchronous neural activity in the brain from sensors placed on the skull. EEG studies have the potential to characterize early neurodevelopmental processes, and unlike eye tracking or other methods, it does not require any overt behavioral response. While EEG has limited spatial resolution, its temporal resolution is excellent, which is used in both time- and frequency-based analyses.

The lack of infant twin EEG studies is surprising given the widespread use of this method in developmental science generally, and the potential value of using noninvasive brain measures to identify heritable psychological traits associated with later neurodevelopmental conditions (e.g., autism; Bosl et al., 2018). Studies of older children have found that EEG measures such as frequency band amplitude are highly heritable (van Baal et al., 1996; Zietsch et al., 2007). However, to our knowledge, only one twin study of infant EEG exists (Orekhova et al., 2003). This cross-sectional study, which included 95 twin pairs, provided evidence for genetic effects on the alpha frequency band in 7- to 12-month-olds, but also tentatively suggested that shared environment could play a role for other EEG measures at this age.

Similarly, we are not aware of any eye tracking studies of twins under the age of 2 years. Eye tracking uses infra-red light to measure the gaze direction of participants while observing stimuli. Eye tracking has been instrumental to our understanding of young infants' attentional, perceptual and emerging cognitive abilities, in both the social and nonsocial domains (Gredebäck et al., 2010). Infants develop flexible gaze behavior earlier than many other behaviors (e.g., crawling), and hence, this method provides a unique window into preverbal development. Eye tracking can also be used to assess the size of the pupil, which has proven to be an informative measure as well (Nyström et al., 2018).

One eye tracking study of 2-year-old twins conducted an analysis of eye movement and gaze characteristics in a relatively small sample ( 83 pairs; Constantino et al., 2017). They found that the tendency to prioritize the eyes versus the mouth during close-up face observation was highly heritable (broad heritability close to $90 \%)$. Further, many lower level aspects of eye movements, such as the timing and spatial direction of saccades, were also more similar in MZ than in DZ twins, although caution is needed in light of the small sample size. In light of the extensive use of eye tracking in developmental science generally, and specifically in studies of infants at risk of autism, there is considerable potential to employ this method in studies of young twins.

Among the small number of infant twin studies using methods from cognitive neuroscience, most have used magnetic resonance imaging (MRI; for a review of these twin studies, see Maggioni et al.,
2020). In terms of differences in brain structure, evidence suggests that genetic factors are important, even very early in life. The magnitude of genetic influence appears to be higher for white matter than grey matter (Gilmore et al., 2010), and region specific (posterior grey matter volume is more heritable than grey matter in frontal areas; Gilmore et al., 2010, see also Duan et al., 2020). Diffusion tensor imaging studies suggest significant heritability of early white matter, but substantial regional differentiation, which may reflect the different developmental or maturational timescales of different white matter tracts; for example, in terms of myelination, as well as time periods with more environmental susceptibility (Geng et al., 2012; Lee et al., 2017; Sadeghi et al., 2017). To our knowledge, only one study has investigated functional MRI in young twins (Gao et al., 2014).

In contrast, there is a larger body of literature of infant twin studies assessing phenotypes such as temperament, sleep and cognition through questionnaires and observational measurements. Studies focused on language and communication in late infancy and toddlerhood show that shared environment accounts for most of the variance ( $60 \%$ ) for measures including imitative ability (McEwen et al., 2007), language acquisition (Harlaar et al., 2008), vocabulary (HayiouThomas et al., 2012; van Hulle et al., 2004), and early verbal ability (Galsworthy et al., 2000). Modest heritability is shown for these type of measures in infancy and early childhood (Dale et al., 2000; Ganger, 1998; Hayiou-Thomas et al., 2012; McEwen et al., 2007; Robinson, 1999; van Hulle et al., 2004). For nonverbal cognitive ability, most studies report low-to-moderate heritability in toddlerhood and early childhood (Bishop et al., 2003; Cherny et al., 1994; Matheny, 1980; Petrill et al., 1998; Petrill et al., 1997; Plomin et al., 1993).

Studies of infant attachment report that shared environmental factors explain a large portion of the variation in the late infancy and toddlerhood period (Bakermans-Kranenburg et al., 2004; Bokhorst et al., 2003; Fearon et al., 2006; Roisman \& Fraley, 2008). These results contrast with studies focusing on parent-child interaction in other contexts than attachment-eliciting situations, which suggest that genetic factors play a substantial role for variation in infant behavior during parent-child interaction, with little contribution from shared environmental factors (Deater-Deckard \& O’Connor, 2000; DiLalla \& Bishop, 1996).

Behavioral genetic research has also included socio-communicative traits. In the last decade, several studies have focused on early emerging behavioral traits linked to autism spectrum disorder (ASD). Overall, such autistic-like traits are moderately to highly heritable in toddlerhood (de Zeeuw et al., 2017; Stilp et al., 2010). Very high heritability estimates have been found for some specific socio-communicative traits, such as attention to eyes and mouth in the second year of life (Constantino et al., 2017), as well as for socio-communicative behaviors rated by parents (Hawks et al., 2019), and reciprocal social behavior (Pohl et al., 2019).

Other areas of early psychopathology and neurodevelopment have been investigated. Hyperactivity was highly heritable in a study with preschool children (2-4 years; Price et al., 2001) with no influences of shared environment. Similarly, the heritability of parent-rated self-control has been estimated to be substantial, with little evidence of shared environmental influences in studies with twins at 2 and 3 years of age (Gagne \& Goldsmith, 2011; Gagne \& Saudino, 2010, 2016).

Emerging ADHD traits can also include executive functioning dimensions of temperament (i.e., effortful control and attention control). Temperament in infancy research is a broad but widely studied phenotype. Twin studies suggest that individual differences in infant and child temperament have a moderate to high 
heritability (Gagne et al., 2009; Planalp \& Goldsmith, 2020; Saudino, 2005), with higher genetic effects for negative aspects of temperament (e.g., anger; Gagne \& Goldsmith, 2011) than positive aspects (e.g., positive affectivity and soothability; Gagne et al., 2009; Goldsmith et al., 1999; Saudino, 2005). Further, motor activity level shows moderate genetic and no shared environment effects (Goldsmith et al., 1999); and significant genetic overlap with ADHD symptoms at 2 years (Ilott et al., 2010).

Temperament is linked to infant sleep, which is crucial for a healthy development. Sleep has been researched in a few twin studies of infants 6 months and older with moderate sample sizes and parent-reported measures. These studies suggest that early childhood daytime sleep may be driven by shared environmental factors to a substantial extent, whereas the variance in nighttime sleep may be more heritable (Brescianini et al., 2011; Dionne et al., 2011; Fisher et al., 2012; Touchette et al., 2013).

Finally, atypical sensory processing (e.g., hyperresponsivity to certain sensory signals; Nyström et al., 2018) are increasingly seen as playing a role in a range of neurodevelopmental disorders, including ASD and ADHD (Dunn, 2002). However, its genetic and environmental influences early in life have not been extensively investigated, with only one twin study done in 1- to 3-year-olds reporting a moderate heritability for sensory defensiveness and a small contribution from shared environment (Goldsmith et al., 2006).

Taken together, while several areas of infant and early child development have been the focus of previous behavioral genetic research, there is considerable potential to expand understanding of the genetic and environmental influences on infant development, particularly in the areas of brain, attentional and behavioral development. Furthermore, some of the most influential studies have either begun at 24 months, thus missing the infancy years, or have been challenged by small samples of under 300 pairs. With BATSS, we took a multimethod approach to perform deep phenotyping of a wide range of traits at five months and followed a sample of 300 twin pairs longitudinally.

The purpose of this article is to describe the BATSS study. We will focus on describing the protocol and procedures, the feasibility of conducting a study of this kind, provide descriptive data about the sample, and discuss putative analysis steps going forward.

\section{Materials and Methods}

\section{The Classic Twin Design}

BATSS employs a classic twin design. Using twin data, the total variance in a trait can be partitioned into genetic variance, common environmental variance and nonshared environmental variance, which incorporates measurement error. $\mathrm{MZ}$ twins share $100 \%$ of their segregating DNA and DZ twins share on average $50 \%$ of their segregating DNA. All twins who are raised together are assumed to share all of their common environmental influences. Differences identified within MZ twin pairs are explained by nonshared environment. As such, when higher within-pair similarity is observed for $\mathrm{MZ}$ than $\mathrm{DZ}$ twins, this pattern is assumed to be due to the role of genetic influences on the trait under investigation (Polderman et al., 2015). Genetic influences are typically modelled as additive effects. Genetic influences can also include nonadditive genetic effects, which are indicated by DZ correlations that are less than half the MZ correlation. Such effects can be estimated in the classical twin design, although not simultaneously with shared environment, as these effects confound one another. In BATSS, the prespecified target sample size was 620 individuals (310 pairs) based on the size of previous twin studies of toddlers (e.g., Ronald et al., 2010). Based on previous twin studies in Sweden, we expected roughly equal numbers of $\mathrm{MZ}$ and $\mathrm{DZ}$ same-sex twin participants.

\section{Study Protocol}

The study protocol is provided in Table 1, which also includes full names of measures and abbreviations. Many of the experiments and instruments align with a longitudinal study of infants at elevated likelihood of ASD/ADHD (Jones et al., 2019). The main rationale behind this is to be able to assess the heritability of putative early ASD/ADHD markers (e.g., Nyström et al., 2021). In addition, specific measures were added for this study, namely the ITC, SDQ, $\mathrm{RBQ}$, three eye tracking tasks (emotional faces, dynamic singing faces, ANS) and one EEG task (form motion). Many eye-tracking and EEG tasks focus on social perception and attention, which is motivated by the abovementioned link to ASD, by the fact that many of these skills and processes emerge early in infancy, and because in older participants, evidence suggest that such socio-cognitive processes may be linked to unique etiological factors not shared with other aspects of cognition (Shakeshaft \& Plomin, 2015).

As many of the tasks and measures are well established, we do not describe them all in detail here, but additional information can be found elsewhere (Jones et al., 2019) or in the original works cited in Table 1. For other measures not described in detail elsewhere, we provide a brief description here.

Demographics and medical/psychiatric history. At the 5-month visit, we administered questionnaires and conducted interviews about basic background information such as date and place of birth, languages spoken in home, occupational and educational status, and family income. Information about the twins' medical conditions was also collected (including twin specific birth complications), as well as the presence of developmental and psychiatric conditions in family and relatives. A set of items surveyed parents' perceived similarity of their infant twins.

\section{Eye-tracking tasks (not described elsewhere).}

Dynamic faces. This eye tracking task consists of dynamic faces ( $n=20$, duration $4-12 \mathrm{~s}$ ), divided into three conditions: singing, nonsinging nursery rhymes and silent. This task measures infants' preference for eyes versus mouth (Constantino et al., 2017; Hunnius \& Geuze, 2004) in the context of naturalistic face stimuli. This task was designed specifically for BATSS, but stimuli properties (e.g., duration) are similar to what has been used previously with infants.

Emotional faces. This task showed triplets of static faces in each stimulus ( $n=12$, duration $5 \mathrm{~s}$ ), of which two were neutral and one had an emotional expression (happy). This task is intended to capture individual differences in attention to emotional facial stimuli, and was adapted from a longitudinal study of social attention.

\section{Biological samples.}

Saliva. Saliva samples were collected by research assistants from all the infant twins using the DNA Genotek OG-575 (DNA Genotek Inc.) collection kit during the study visit.

Hair. A lock of hair was cut from the posterior vertex region of the head by parents, as close to the scalp as possible. 
Table 1. BATSS protocol

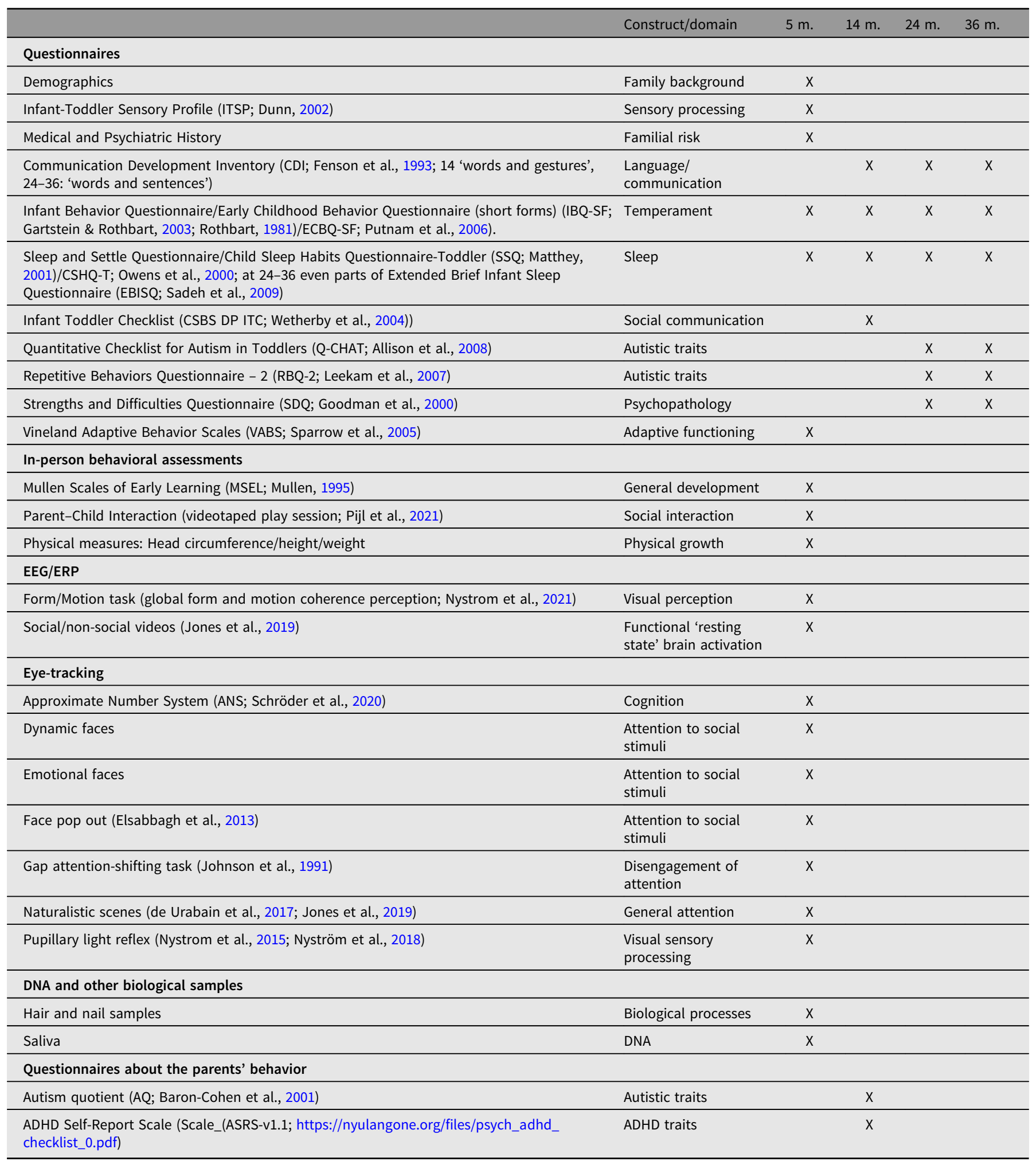

Nails. Samples of at least $4 \mathrm{~mm}$ in length were collected from fingernails and toenails. Hair and nail samples were collected to assess metabolic changes over time related to prenatal and early postnatal exposures to metals and/or other substances.

\section{Recruitment and Testing Procedure}

Recruitment and first telephone interview. Same-sex twin families were identified via the Swedish Population Registry (Folkbokföringsregistret, hosted by the Swedish Tax Agency). In 
total, 1068 families with same-sex twins were invited to join the study via letters. If families agreed to participate during a follow-up telephone call, a screening interview was performed. To be included in the study, the twins had to hear Swedish at home from at least one parent and live with at least one biological parent. Parents also needed to be willing to share information about medical and psychiatric history in the family, demographic background and delivery. Reasons for exclusion were hearing or vision impairments, premature birth (defined as prior to week 34 of gestation), epilepsy or seizures, medical conditions that were likely to affect brain development, ability to participate in the study, and the presence of known genetic syndromes. In a few cases, we included and tested twins with ambiguous medical conditions (12 pairs with twin-to-twin transfusion syndrome reported by parents, one twin with low birth weight, one twin with spina bifida, and two twins with seizures at birth; these are included in the total sample described in this article). The study was approved by the Regional Ethics Board in Stockholm, and parents provided informed written consent to participate in the research.

Five month in-person visit at the lab. At age 4-5 months, a letter was sent home to the parents with information about the visit, printed questionnaires and directions for completing online questionnaires (see Table 1 for overview).

The 5-month visit was typically performed in one day, lasting approximately five hours. At least two research assistants were present, each having the responsibility for specific tasks. During the visit, the twins were called by their actual names in communication with their parents, and each twin had their own personal 'schedule'. This enabled the research assistants to keep track of the tasks performed and minimized the risk of mixing the twins up. If the research assistants had difficulty telling them apart, due to the twins being very alike and/or dressed similarly, stickers with the numbers ' 1 ' and ' 2 ' were placed on their abdomens. The twins performed different tasks at the same time and we generally encouraged both parents to be present during the visit, so that each child could be accompanied by one caregiver in all tasks. When occasionally it was not possible for both parents to attend the visit (i.e., only one parent being able to take leave from work or in single parent households), we had a third research assistant present acting as a 'stand-in'. If this was the case, we always informed the parent(s) prior to the visit, to verify that this was acceptable to them. Occasionally, other relatives and friends could be present and to assist in such cases.

We started with performing the tasks that were most demanding for the infants, namely EEG (approximately $11 \mathrm{~min}$ ), and the Mullen Scales of Early Learning (MSEL; approx. 10-15 min). Later in the visit, we performed Eye Tracking (several experiments in two separate sessions; approximately 6 and $10 \mathrm{~min}$, respectively) and Parent-Child Interaction (PCI), a playtime with the mother and one twin at a time that was video recorded for subsequent behavioral coding (approximately $15 \mathrm{~min}$ ). However, the order of tasks was not entirely fixed and varied depending on the moods and needs of the twins.

We took breaks when needed to let the twins rest and eat. In the middle of the day, we had a longer break for lunch and carried out parent report interviews (about demographic details such as education and employment, as well as medical and psychiatric history in relatives; see Table 1). The parents received gift vouchers as compensation for participating.
Follow-up questionnaire packages (14-36 months). The twins were followed up through online questionnaires at 14, 24 and 36 months (see Table 1 for a full overview of included questionnaires). At these ages, we sent a letter with detailed instructions about the questionnaires and log-in information, together with a gift voucher. If the questionnaires were not completed after two weeks, we sent a brief reminder via email. If the questionnaires were not completed after a month, we initially sent a reminder letter, but this routine was later changed to a phone call to assist the parents with any questions or technical issues. The last date for the parents to complete the questionnaire before the time point was considered passed was at 15 months for the 14-months' time point and 30 months for the 24-months' time point; for the 36-months' time point there was no last date for completion. The exact time point of questionnaire competition was recorded, allowing for further age-based selection and analysis if needed.

\section{Sample collection and genotyping}

Saliva samples were collected from all the infant twins using the DNA Genotek OG-575 collection kit during the study visit. All saliva samples were stored and processed for DNA extraction at the Karolinska Institutet Biobank. DNA extraction was done using Chemagen kits based on magnetic bead separation using the automated Hamilton ChemagicSTAR ${ }^{\circledast}$ platform. DNA quantity and quality was checked before proceeding to genotyping. The twins were genotyped using the Illumina Infinium Global Screening Array version 3 Infinium Assay using standard protocols at the SNP\&SEQ Technology Platform at Uppsala University.

\section{Results}

\section{Recruitment Summary}

In total, 1068 families were invited to participate in BATSS. Because we recruited from the Swedish Population Registry, these individuals represent most same-sex twins born in the targeted area during the period in question (Supplementary Figure S1). In total, $46.9 \%$ of the invited families responded to our recruitment materials and could be interviewed by telephone. A total of 567 (53.1\%) of the invited families did not participate, even though brief reminder letters were sent to most of them. Figure 1 outlines the categories of reasons given by families who did not participate.

\section{Sample Characterization}

Table 2 summarizes the main characteristics of the final BATSS sample, as well as $\mathrm{MZ}$ and $\mathrm{DZ}$ subsamples. As can be seen, the total sample consists of 311 twin pairs, of whom 177 are MZ and 134 are DZ. All twin pairs in the BATSS sample were same-sex, with 151 pairs being female and 160 male. All pairs lived in the greater Stockholm and Uppsala area in Sweden upon recruitment, with 27.6\% living in central Stockholm. Supplementary Table S1 summarizes response rates for online questionnaires.

To further assess the representativeness of our sample, we compared socioeconomic status of our sample with the population of Stockholm and Sweden as a whole, using statistics from Statistiska Centralbyrån ('Statistics Sweden', SCB; Table 3).

\section{Molecular Genetic Analyses}

Quality control and imputation. In 117 pairs of MZ twins (whose zygosity was confirmed earlier via a simplified genetic analysis; 


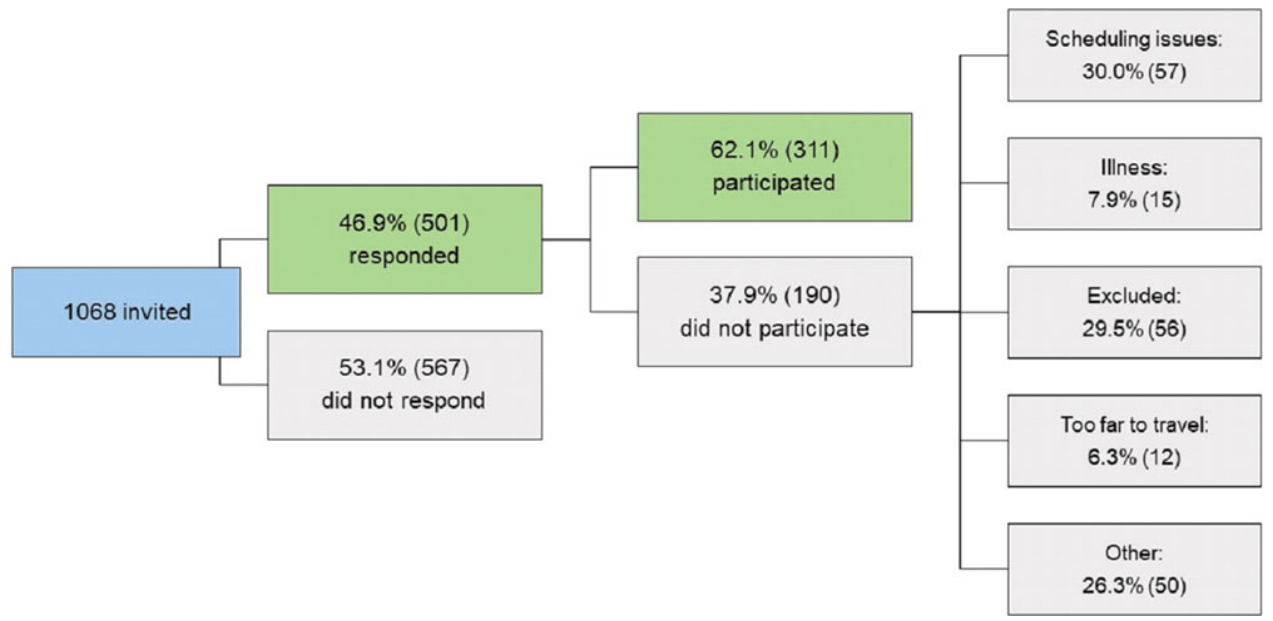

Figure 1. Overall recruitment statistics

studies employing eye tracking and EEG. Further, few twin studies of infants have included a comprehensive, longitudinal protocol spanning behavior and brain measures and covering psychological constructs from early basic perception to later language skills. By introducing eye tracking and EEG methodologies, the current study can help us understand the etiological factors behind a range of informative processes ranging from low level perception and attention to complex behaviors. The multilevel, longitudinal protocol, which includes both these novel methods and more classical assessment approaches, has the potential to provide a more complete picture of cognitive and brain development than has been possible before.

The study shows that it is possible to recruit a relatively large number of infant twin families and assess them at a steady pace within a medium-sized metropolitan area (greater Stockholm area $\sim 2$ million people; Supplementary Figure S1). The relatively high final inclusion rate (approximately $29 \%$ of the population in the targeted area; Figure 1), despite requiring in-person visits to the lab, suggests high motivation among infant twin parents to participate in research in Sweden. It is notable that initially, nearly $50 \%$ of the target population were interested in participating (Figure 1), but some were ultimately not able due to scheduling issues or not fulfilling inclusion criteria. In addition, while $53.1 \%$ of the targeted population did not respond to our materials, this does not necessarily mean that all these families were negative to participation. Taken together, we conclude that the motivation to participate in research is very high among parents of infant twins in Sweden: At least about half of the population is interested in participation in principle. This may reflect general interest in research and an appreciation of the fact that twins are particularly valuable for science (Sweden has a strong tradition of twin research of older children and adults; e.g., Anckarsäter et al., 2011; Zagai et al., 2019), but it can also reflect other factors such as generous parental benefits in Sweden, which allow parents to participate with few practical or economic negative consequences.

Importantly, the study shows that it is possible to conduct multimethod assessments within cognitive neuroscience (brain-based measurements, direct behavioral assessments, questionnaires, biosamples) from two infant twins within one day. Again, this may reflect the generous parental benefits in Sweden allowing both parents to be on leave at the same time, and thus both present during testing. However, it is manageable to conduct the research with only one parent, and extra research assistants. Taken together, the 
Table 2. Participant characteristics ${ }^{1}$

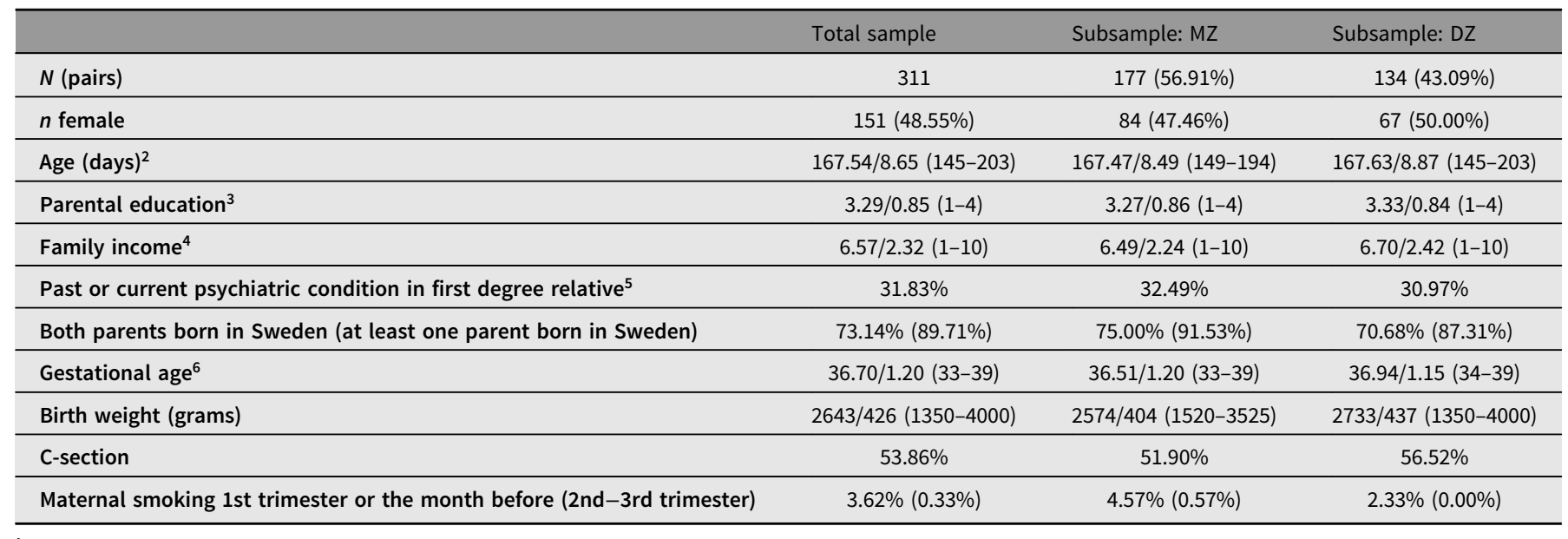

${ }^{1} n$ for individual variables vary slightly (298-311 pairs).

${ }^{2} \mathrm{Age}$ at 5 months assessment. Mean/SD [min max]; this format applies generally unless otherwise specified.

${ }^{3}$ Education level on a scale from 1 to 4 , where $1=$ Primary, $2=$ Secondary, $3=$ Undergraduate ( $\leq 3$ years) and $4=$ Postgraduate level $(>3$ years).

${ }^{4}$ Family income per month. Scale $1-10$ where $1=<20 \mathrm{~K}, 2=20-30 \mathrm{~K}, 3=30-40 \mathrm{~K}, 4=40-50 \mathrm{~K}, 5=50-60 \mathrm{~K}, 6=60-70 \mathrm{~K}, 7=70-80 \mathrm{~K}, 8=80-90 \mathrm{~K}, 9=90-100 \mathrm{~K}$ and $10=>100 \mathrm{~K}(\mathrm{SEK})$.

${ }^{5}$ Reported past/current ASD, ADHD, intellectual disability, panic or anxiety disorder, depression, bipolar disorder, schizophrenia and/or admittance to psychiatric care of mother, father or full siblings of the whole sample. Classified binarily ( $1=$ yes to at least one, $0=$ no to all).

${ }^{6}$ Gestational age of the whole sample as defined by the number of completed gestational weeks. One pair was born in week $33+6$ (weeks + days).

Table 3. Socioeconomic status

\begin{tabular}{lcccccccc}
\hline & \multicolumn{3}{c}{ Education $^{1}$} & & \multicolumn{3}{c}{ Income $^{2}$} \\
\cline { 2 - 5 } \cline { 6 - 8 } & Primary & Secondary & Tertiary & & Low & Medium & High \\
\hline BATSS & $0.96 \%$ & $15.06 \%$ & $83.97 \%$ & & $19.34 \%$ & $54.01 \%$ & $26.64 \%$ \\
\hline Stockholm $^{3}$ & $6.97 \%$ & $28.30 \%$ & $64.73 \%$ & $44.19 \%$ & $38.74 \%$ & $17.08 \%$ \\
\hline Sweden $^{3}$ & $8.53 \%$ & $34.17 \%$ & $57.30 \%$ & $51.31 \%$ & $38.97 \%$ & $9.72 \%$ \\
\hline
\end{tabular}

Note: ${ }^{1}$ Mothers' highest level of completed education (primary $(\leq 10$ years of education on ISCED levels $1-2$ ), secondary ( $\leq 3$ years of education on ISCED levels $3-4)$ and tertiary ( $>0$ years of education on ISCED levels 5-8)). Education levels represent the ISCED levels of education (UNESCO Institute for Statistics, 2012). ${ }^{2}$ Mothers' yearly income (low: $\leq 299 \mathrm{~K}$ SEK medium: $300-499 \mathrm{~K}$ SEK and high: $\geq 500 \mathrm{~K}$ SEK), mean age 34 years. ${ }^{3}$ For comparison, we have included data showing the income and education of the population of Stockholm county and Sweden, compiled 2019 (women aged between 25-44 years; source Statistiska Centralbyrån, SCB).

BATSS study demonstrates high feasibility of comprehensive infant twin studies in other areas with similar societal and geographical characteristics.

There was a slight bias toward MZ twins in the sample (Table 1). This may reflect true differences in rates of $M Z$ versus DZ among same-sex twins, but is likely to reflect higher interest in participating in research in MZ twin families. There was a nearequal distribution of females versus males, both in the total sample and in the separate $\mathrm{MZ}$ and $\mathrm{DZ}$ groups. While the age range (4.8-6.7 months, mean 5.5 months) is relatively narrow, we will take age into account in data analyses (e.g., use as covariate). Indeed, this age range is marked by considerable development across many domains of cognitive and brain development.

The MZ and DZ groups were similar in terms of age, parental education, income, psychiatric family history, and region or country of birth of parents. Because twin analyses build on comparisons between $\mathrm{MZ}$ and DZ twins, it simplifies analysis and interpretation that these groups do not differ on background variables. Further, $\mathrm{MZ}$ and DZ groups were similar in terms of gestational age and frequency of C-section. MZ twins were around $200 \mathrm{~g}$ lighter at birth compared to $\mathrm{DZ}$ twins $(p=.001)$. While this difference was marginal at the descriptive level, it could be important to include birth weight as a covariate in analyses.

Compared to the mean of the general Stockholm population, the sample had a higher average level of formal education and somewhat higher average income (Table 3 ). This difference is consistent with studies of older twins in Sweden (e.g., Taylor et al., 2020) and should be taken into account in any findings from the study. Little is known about how socio-economic status may moderate heritability estimates in early infancy (for an example of this phenomenon in young children, see Turkheimer et al., 2003), but as with all twin samples, the results should be considered in light of the sample characteristics.

Within the framework of the classical twin design, both univariate and multivariate analyses will be conducted. Given the young age of the participants, it is of particular interest to compare heritability and estimates of environmental influence for the different types of measures, to understand which aspects of development are under relatively higher versus lower genetic and environmental influence. Further, extending the classic twin design to include measures of the environment (such as the parent's behavior during parent-child interaction) will also help us understand to what extent the child's genetic predispositions affect their social environment (e.g., DiLalla \& Bishop, 1996; Kennedy et al., 2017). It is also of primary interest to understand the genetic landscape across different phenotypes (multivariate twin modelling) to understand to what extent development within and across domains is influenced by a set of shared versus unique genetic and environmental factors. Ultimately, it will also be beneficial, to both the behavioral genetic and development science fields, to account for our longitudinal design in multivariate models to study genetic and environmental continuity and change in cognitive and brain development across the first few years of life.

In addition to comparing similarity in $\mathrm{MZ}$ versus $\mathrm{DZ}$ twins (classic twin analyses), we will be able to capitalize on MZ differences within the sample, based on the logic that if MZ twins are different, it must reflect differences in nonshared environment (but see Jonsson et al., 2021). This design can be powerful in 
identifying (or falsifying) potential causal pathways linked to environmental exposures. For example, research has shown atypical concentration of certain metals in the teeth of children with autism already in infancy (Arora et al., 2017). We can use similar analyses to check whether any differences in metal concentration in nails or hair in MZ twins correlate with differences in development within MZ pairs.

The sample has been genotyped and polygenic scores have been calculated for all individuals who provided DNA samples and who passed our quality control stages. Therefore, our study is in a position to be able to contribute to an understanding of how the common genetic architecture in neurodevelopmental conditions, such as autism and ADHD, and traits and conditions that affect people in later life, such as educational attainment and schizophrenia, influence cognitive and brain development in the first months of life, long before these conditions or traits have emerged (for a recent example of this approach in infancy research, see Gui et al., 2020). Polygenic score analyses will be conducted in the sample, and we hope the sample can also be used more broadly to advance understanding of the genetic basis of neurodevelopmental, cognitive and psychiatric phenotypes. At present, molecular genetic research on infancy lags far behind research on older samples (Papageorgiou \& Ronald, 2013, 2017); the potential to work with the genetic data within the sample represents another opportunity afforded by the BATSS dataset.

Supplementary Material. To view supplementary material for this article, please visit https://doi.org/10.1017/thg.2021.34.

Acknowledgments. The authors thank all participating families, as well as research assistants Joy Hättestrand, Johanna Kronqvist, Sofia Jönsson, Anna Kernell, Carolin Schreiner, Sophie Lingö, Angelinn Liljebäck, Isabelle Enedahl, Matthis Andreasson, Lisa Belfrage, Mattias Savallampi, Isabelle Ocklind and Hjalmar Nobel Norrman. The authors thank Professor Paul Lichtenstein for general support.

Author Contribution. Conceptualization: TFY with contributions from AR, SB, KT; Methodology: TFY, KT, AR, MT, SB, LW; Formal analysis: LH, KT, DL, CW, IH; Data curation: TFY, LH; Investigation: MS, LH, LM; Writing (original draft): TFY with contributions from AR, MS, AMP, LH, CW; Writing (review and editing): all authors; Supervision: TFY with contributions from AR, MT. Visualization: DL, LH, AMP; Project administration: TFY with contributions from LH, MS; Funding acquisition: TFY, AR, KT, SB.

Financial Support. The work leading to these results were supported by Stiftelsen Riksbankens Jubileumsfond (NHS14-1802:1; Pro Futura Scientia [in collaboration with SCAS]); the Swedish Research Council (2018-06232); Knut and Alice Wallenberg foundation; and the European Union (Initial Training Network BRAINVIEW; 642996). LT and DL were supported by the Swedish Foundation for Strategic Research FFL18-0104 and China Scholarship Council. We acknowledge the KI Biobank for handling the biological samples, SNP\&SEQ Technology platform at Uppsala University for genotyping and the Swedish National Infrastructure for Computing (SNIC) at UPPMAX, partially funded by the Swedish Research Council through grant agreement no. 2018-05973" for computations.

Conflict of Interest. The authors declare no conflict of interest related to this article. SB discloses that he has in the last 3 years acted as an author, consultant or lecturer for Medice and Roche. He receives royalties for textbooks, diagnostic and intervention tools from Hogrefe Publishers.

Ethical Standards. The authors assert that all procedures contributing to this work comply with the ethical standards of the relevant national and institutional committees on human experimentation and with the Helsinki Declaration of 1975 , as revised in 2008 .

\section{References}

Allison, C., Baron-Cohen, S., Wheelwright, S., Charman, T., Richler, J., Pasco, G., \& Brayne, C. (2008). The Q-CHAT (Quantitative Checklist for Autism in Toddlers): a normally distributed quantitative measure of autistic traits at 18-24 months of age: preliminary report. Journal of Autism And Developmental Disorders, 38, 1414-1425.

Ameur, A., Dahlberg, J., Olason, P., Vezzi, F., Karlsson, R., Martin, M., Viklund, J., Kähäri, A. K., Lundin, P., Che, H., Thutkawkorapin, J., Eisfeldt, J., Lampa, S., Dahlberg, M., Hagberg, J., Jareborg, N., Liljedahl, U., Jonasson, I., Johansson, Å., ... Gyllensten, U. (2017). SweGen: A whole-genome data resource of genetic variability in a cross-section of the Swedish population. European Journal of Human Genetics, 25, 1253-1260.

Anckarsäter, H., Lundstrom, S., Kollberg, L., Kerekes, N., Palm, C., Carlstrom, E., Långström, N, Magnusson, P. K., Halldner, L., Bölte, S., Gillberg, C., Gumpert, C., Råstam, M., \& Lichtenstein, P. (2011). The Child and Adolescent Twin Study in Sweden (CATSS). Twin Research and Human Genetics, 14, 495-508.

Arora, M., Reichenberg, A., Willfors, C., Austin, C., Gennings, C., Berggren, S., Lichtenstein, P, Anckarsäter, H., Tammimies, K, \& Bölte, S. (2017). Fetal and postnatal metal dysregulation in autism. Nature Communications, 8, 15493.

Bakermans-Kranenburg, M., Van Uzendoorn, M., Bokhorst, C., \& Schuengel, C. (2004). The importance of shared environment in infantfather attachment: A behavioral genetic study of the attachment q-sort. Journal of Family Psychology, 18, 545.

Baron-Cohen, S., Wheelwright, S., Skinner, R., Martin, J., \& Clubley, E. (2001). The autism-spectrum quotient (AQ): Evidence from asperger syndrome/high-functioning autism, males and females, scientists and mathematicians. Journal of Autism and Developmental Disorders, 31, 5-17.

Bishop, E., Cherny, S. S., Corley, R., Plomin, R., DeFries, J. C., \& Hewitt, J. K. (2003). Development genetic analysis of general cognitive ability from 1 to 12 years in a sample of adoptees, biological siblings, and twins. Intelligence, $31,31-49$.

Bokhorst, C. L., Bakermans-kranenburg, M. J., Pasco Fearon, R., Van Ijzendoorn, M. H., Fonagy, P., \& Schuengel, C. (2003). The importance of shared environment in mother-infant attachment security: A behavioral genetic study. Child Development, 74, 1769-1782.

Bosl, W. J., Tager-Flusberg, H., \& Nelson, C. A. (2018). EEG analytics for early detection of autism spectrum disorder: a data-driven approach. Scientific Reports, 8, 6828.

Brescianini, S., Volzone, A., Fagnani, C., Patriarca, V., Grimaldi, V., Lanni, R., Serino, L., Mastroiacovo, P., \& Stazi, M. A. (2011). Genetic and environmental factors shape infant sleep patterns: a study of 18-month-old twins. Pediatrics, 127, e1296-e1302.

Cherny, S. S., Fulker, D., Emde, R., Robinson, J., Corley, R., Reznick, J., Plomin, R., \& DeFries, J. (1994). A developmental-genetic analysis of continuity and change in the Bayley Mental Development Index from 14 to 24 months: The MacArthur Longitudinal Twin Study. Psychological Science, 5, 354-360.

Cicchetti, D., \& Rogosch, F. A. (1996). Equifinality and multifinality in developmental psychopathology. Development and Psychopathology, 8, 597-600. Constantino, J. N., Kennon-McGill, S., Weichselbaum, C., Marrus, N., Haider, A., Glowinski, A. L., Gillespie, S., Klaiman, C., Klin, A., \& Jones, W. (2017). Infant viewing of social scenes is under genetic control and is atypical in autism. Nature, 547, 22999.

Dale, P. S., Dionne, G., Eley, T. C., \& Plomin, R. (2000). Lexical and grammatical development: A behavioural genetic perspective. Journal of Child Language, 27, 619-642.

de Urabain, I. R. S., Nuthmann, A., Johnson, M. H., \& Smith, T. J. (2017). Disentangling the mechanisms underlying infant fixation durations in scene perception: A computational account. Vision Research, 134, 43-59.

de Zeeuw, E. L., van Beijsterveldt, C. E., Hoekstra, R. A., Bartels, M., \& Boomsma, D. I. (2017). The etiology of autistic traits in preschoolers: a population-based twin study. Journal of Child Psychology and Psychiatry, 58, 893-901. 
Deater-Deckard, K., \& O'Connor, T. G. (2000). Parent-child mutuality in early childhood: Two behavioral genetic studies. Developmental Psychology, 36, 561-570.

Demontis, D., Walters, R. K., Martin, J., Mattheisen, M., Als, T. D., Agerbo, E., Baldursson, G., Belliveau, R., Bybjerg-Grauholm, J., Bækvad-Hansen, M., Cerrato, F., Chambert, K., Churchhouse, C., Dumont, A., Eriksson, N., Gandal, M., Goldstein, J. I., Grasby, K. L., Grove, J., ... BækvadHansen, M. (2019). Discovery of the first genome-wide significant risk loci for attention deficit/hyperactivity disorder. Nature Genetics, 51, 63-75.

DiLalla, L. F., \& Bishop, E. (1996). Differential maternal treatment of infant twins: Effects on infant behaviors. Behavior Genetics, 26, 535-542.

Dionne, G., Touchette, E., Forget-Dubois, N., Petit, D., Tremblay, R. E., Montplaisir, J. Y., \& Boivin, M. (2011). Associations between sleep-wake consolidation and language development in early childhood: a longitudinal twin study. Sleep, 34, 987-995.

Duan, D., Xia, S., Rekik, I., Wu, Z., Wang, L., Lin, W., Gilmore, J. H., Shen, D., \& Li, G. (2020). Individual identification and individual variability analysis based on cortical folding features in developing infant singletons and twins. Human Brain Mapping, 41, 1985-2003.

Dunn, W. (2002). Infant-Toddler Sensory Profile: User's manual. Psychological Corporation.

Elsabbagh, M., Gliga, T., Pickles, A., Hudry, K., Charman, T., Johnson, M. H., \& Team, B. (2013). The development of face orienting mechanisms in infants at-risk for autism. Behavioural Brain Research, 251, 147-154.

Fearon, R., Van IJzendoorn, M. H., Fonagy, P., Bakermans-Kranenburg, M. J., Schuengel, C., \& Bokhorst, C. L. (2006). In search of shared and nonshared environmental factors in security of attachment: a behavior-genetic study of the association between sensitivity and attachment security. Developmental Psychology, 42, 1026.

Fenson, L., Dale, P. S., Reznick, J. S., Thal, D., Bates, E., Hartung, J., Pethick, S., \& Reilly, J. S. (1993). Communicative development inventories: User's guide and technical manual. Singular Publishing Group.

Fisher, A., van Jaarsveld, C. H., Llewellyn, C. H., \& Wardle, J. (2012). Genetic and environmental influences on infant sleep. Pediatrics, 129, 1091-1096.

Gagne, J. R., \& Goldsmith, H. H. (2011). A longitudinal analysis of anger and inhibitory control in twins from 12 to 36 months of age. Developmental Science, 14, 112-124.

Gagne, J. R., \& Saudino, K. J. (2010). Wait for it! A twin study of inhibitory control in early childhood. Behavior Genetics, 40, 327-337.

Gagne, J. R., \& Saudino, K. J. (2016). The development of inhibitory control in early childhood: A twin study from 2-3 years. Developmental Psychology, 52, 391.

Gagne, J. R., Vendlinski, M. K., \& Goldsmith, H. H. (2009). The genetics of childhood temperament. In Y.-K. Kim (Ed.), Handbook of behavior genetics (pp. 251-267). Springer Science + Business Media. https://doi.org/10.1007/ 978-0-387-76727-7_18

Galsworthy, M. J., Dionne, G., Dale, P. S., \& Plomin, R. (2000). Sex differences in early verbal and non-verbal cognitive development. Developmental Science, 3, 206-215.

Ganger, J. B. (1998). Genes and environment in language acquisition: A study of early vocabulary and syntactic development in twins. Massachusetts Institute of Technology.

Gao, W., Elton, A., Zhu, H., Alcauter, S., Smith, J. K., Gilmore, J. H., \& Lin, W. (2014). Intersubject variability of and genetic effects on the brain's functional connectivity during infancy. Journal of Neuroscience, 34, 11288-11296. Gartstein, M. A., \& Rothbart, M. K. (2003). Studying infant temperament via the revised infant behavior questionnaire. Infant Behavior and Development, 26, 64-86.

Ge, T., Chen, C.-Y., Ni, Y., Feng, Y.-C. A., \& Smoller, J. W. (2019). Polygenic prediction via Bayesian regression and continuous shrinkage priors. Nature Communications, 10, 1-10.

Geng, X., Prom-Wormley, E. C., Perez, J., Kubarych, T., Styner, M., Lin, W., Neale, M. C., \& Gilmore, J. H. (2012). White matter heritability using diffusion tensor imaging in neonatal brains. Twin Research and Human Genetics, 15, 336-350.

Gibbs, R. A., Belmont, J. W., Hardenbol, P., Willis, T. D., Yu, F., Yang, H., Ch'ang, L. Y., Huang, W., Liu, B., Shen, Y., Tam, P. K. H., Tsui, L. C.,
Waye, M. M. Y., Wong, J. T. F., Zeng, C. Q., Zhang, Q. R., Chee, M. S., Galver, L. M., Kruglyak, S., ... Tanaka, T. (2003). The International Hapmap Project. Deep Blue, University of Michigan.

Gilmore, J. H., Schmitt, J. E., Knickmeyer, R. C., Smith, J. K., Lin, W., Styner, M., Gerig, G., \& Neale, M. C. (2010). Genetic and environmental contributions to neonatal brain structure: A twin study. Human Brain Mapping, 31, 1174-1182.

Goldsmith, H. H., Lemery, K. S., Buss, K. A., \& Campos, J. J. (1999). Genetic analyses of focal aspects of infant temperament. Developmental Psychology, 35, 972.

Goldsmith, H. H., Van Hulle, C. A., Arneson, C., Schreiber, J., \& Gernsbacher, M. (2006). A population-based twin study of parentally reported tactile and auditory defensiveness in young children. Journal of Abnormal Child Psychology, 34, 378-392.

Goodman, R., Ford, T., Simmons, H., Gatward, R., \& Meltzer, H. (2000). Using the Strengths and Difficulties Questionnaire (SDQ) to screen for child psychiatric disorders in a community sample. The British Journal of Psychiatry, 177, 534-539.

Gottlieb, G. (2007). Probabilistic epigenesis. Developmental Science, 10, 1-11. Gredebäck, G., Johnson, S., \& von Hofsten, C. (2010). Eye tracking in infancy research. Developmental Neuropsychology, 35, 1-19.

Grove, J., Ripke, S., Als, T. D., Mattheisen, M., Walters, R. K., Won, H., Pallesen, J., Agerbo, E., Andreassen, O. A., Anney, R., Awashti, S., Belliveau, R., Bettella, F., Buxbaum, J. D., Bybjerg-Grauholm, J., Bækvad-Hansen, M., Cerrato, F., Chambert, K., Christensen, J. H., Churchhouse, C., Dellenvall, K., Demontis, D., De Rubeis, S., .. Børglum, A. D. (2019). Identification of common genetic risk variants for autism spectrum disorder. Nature Genetics, 51, 431-444.

Gui, A., Mason, L., Gliga, T., Hendry, A., Begum Ali, J., Pasco, G., Shephard, E., Curtis, C., Charman, T., Johnson, M. H., Meaburn, E., \& Jones, E. J. H. (2020). Look duration at the face as a developmental endophenotype: Elucidating pathways to autism and ADHD. Development and Psychopathology, 32, 1303-1322.

Hannelius, U., Gherman, L., Mäkelä, V.-V., Lindstedt, A., Zucchelli, M., Lagerberg, C., Tybring, G., Kere, J., \& Lindgren, C. M. (2007). Large-scale zygosity testing using single nucleotide polymorphisms. Twin Research and Human Genetics, 10, 604-625.

Harlaar, N., Hayiou-Thomas, M. E., Dale, P. S., \& Plomin, R. (2008). Why do preschool language abilities correlate with later reading? A twin study. Journal of Speech, Language, and Hearing Research, 51, 688-705.

Hawks, Z. W., Marrus, N., Glowinski, A. L., \& Constantino, J. N. (2019). Early origins of autism comorbidity: Neuropsychiatric traits correlated in childhood are independent in infancy. Journal of Abnormal Child Psychology, 47, 369-379.

Hayiou-Thomas, M. E., Dale, P. S., \& Plomin, R. (2012). The etiology of variation in language skills changes with development: A longitudinal twin study of language from 2 to 12 years. Developmental Science, 15, 233-249. Howard, D. M., Adams, M. J., Clarke, T.-K., Hafferty, J. D., Gibson, J., Shirali, M., Coleman, J. R. I., Hagenaars, S. P., Ward, J., Wigmore, E. M., Alloza, C., Shen, X., Barbu, M. C., Xu, E. Y., Whalley, H. C., Marioni, R. E., Porteous, D. J., Davies, G., Deary, I. J., ... McIntosh, A M. (2019). Genome-wide meta-analysis of depression identifies 102 independent variants and highlights the importance of the prefrontal brain regions. Nature Neuroscience, 22, 343-352.

Howie, B. N., Donnelly, P., \& Marchini, J. (2009). A flexible and accurate genotype imputation method for the next generation of genome-wide association studies. PLoS Genetics, 5, e1000529.

Hunnius, S., \& Geuze, R. H. (2004). Developmental changes in visual scanning of dynamic faces and abstract stimuli in infants: A longitudinal study. Infancy, 6, 231-255.

Ilott, N., Saudino, K. J., Wood, A., \& Asherson, P. (2010). A genetic study of ADHD and activity level in infancy. Genes, Brain and Behavior, 9, 296-304. Johnson, M. H., Posner, M. I., \& Rothbart, M. K. (1991). Components of visual orienting in early infancy: Contingency learning, anticipatory looking, and disengaging. Journal of Cognitive Neuroscience, 3, 335-344.

Jones, E. J. H., Mason, L., Begum Ali, J., van den Boomen, C., Braukmann, R., Cauvet, E., Demurie, E., Hessels, R. S., Ward, E. K., Hunnius, S., Bolte, S., Tomalski, P., Kemner, C., Warreyn, P., Roeyers, H., Buitelaar, J., 
Falck-Ytter, T., Charman, T., Johnson, M. H., \& Eurosibs Team. (2019). Eurosibs: Towards robust measurement of infant neurocognitive predictors of autism across Europe. Infant Behavior and Development, 57, 101316.

Jonsson, H., Magnusdottir, E., Eggertsson, H. P., Stefansson, O. A., Arnadottir, G. A., Eiriksson, O., Zink, F., Helgason, E. A., Jonsdottir, I., Gylfason, A., Jonasdottir, A., Jonasdottir, A., Beyter, D., Steingrimsdottir, T., Norddahl, G. L., Magnusson, O. T., Masson, G., Halldorsson, B. V., Thorsteinsdottir, U., .. Stefansson, K. (2021). Differences between germline genomes of monozygotic twins. Nature Genetics, 53, 27-34.

Kennedy, D. P., D’Onofrio, B. M., Quinn, P. D., Bölte, S., Lichtenstein, P., \& Falck-Ytter, T. (2017). Genetic influence on eye movements to complex scenes at short timescales. Current Biology, 27, 3554-3560.

Lee, J. J., Wedow, R., Okbay, A., Kong, E., Maghzian, O., Zacher, M., Nguyen-Viet, T. A., Bowers, P., Sidorenko, J., Karlsson Linnér, R., Fontana, M. A., Kundu, T., Lee, C., Li, H., Li, R., Royer, R., Timshel, P. N., Walters, R. K., Willoughby, E. A., Yengo, L.; 23andMe Research Team; COGENT (Cognitive Genomics Consortium), Social Science Genetic Association Consortium, Alver, M., Bao, Y., ... Cesarini, D. (2018). Gene discovery and polygenic prediction from a genome-wide association study of educational attainment in 1.1 million individuals. Nature Genetics, 50, 1112-1121.

Lee, S. J., Steiner, R. J., Yu, Y., Short, S. J., Neale, M. C., Styner, M. A., Zhu, H., \& Gilmore, J. H. (2017). Common and heritable components of white matter microstructure predict cognitive function at 1 and $2 \mathrm{y}$. Proceedings of the National Academy of Sciences, 114, 148-153.

Leekam, S., Tandos, J., McConachie, H., Meins, E., Parkinson, K., Wright, C., Turner, M., Arnott, B., Vittorini, L., \& Couteur, A. L. (2007). Repetitive behaviours in typically developing 2-year-olds. Journal of Child Psychology and Psychiatry, 48, 1131-1138.

Maggioni, E., Squarcina, L., Dusi, N., Diwadkar, V. A., \& Brambilla, P. (2020). Twin MRI studies on genetic and environmental determinants of brain morphology and function in the early lifespan. Neuroscience and Biobehavioral Reviews, 109, 139-149.

Matheny Jr., A. P. (1980). Bayley's Infant Behavior Record: Behavioral components and twin analyses. Child Development, 51, 1157-1167.

Matthey, S. (2001). The sleep and settle questionnaire for parents of infants: psychometric properties. Journal of Paediatrics and Child Health, 37, 470-475. McEwen, F., Happé, F., Bolton, P., Rijsdijk, F., Ronald, A., Dworzynski, K., \& Plomin, R. (2007). Origins of individual differences in imitation: Links with language, pretend play, and socially insightful behavior in two-yearold twins. Child Development, 78, 474-492.

Mullen, E. M. (1995). Mullen Scales of Early Learning: AGS edition. Circle Pines.

Nyström, P., Gliga, T., Nilsson Jobs, E., Gredebäck, G., Charman, T., Johnson, M., Bölte, S., \& Falck-Ytter, T. (2018). Enhanced pupillary light reflex in infancy is associated with autism diagnosis in toddlerhood. Nature Communications, 9, 1678

Nystrom, P., Gredeback, G., Bolte, S., \& Falck-Ytter, T. (2015). Hypersensitive pupillary light reflex in infants at risk for autism. Molecular Autism, 6, Article no. 10.

Nystrom, P., Jones, E., Darki, F., Bolte, S., \& Falck-Ytter, T. (2021). Atypical topographical organization of global form and motion processing in 5month-old infants at risk for autism. Journal of Autism and Developmental Disorders, 51, 364-370.

Orekhova, E. V., Stroganova, T. A., Posikera, I. N., \& Malykh, S. B. (2003). Heritability and 'environmentability' of electroencephalogram in infants: the twin study. Psychophysiology, 40, 727-741.

Owens, J. A., Spirito, A., \& McGuinn, M. (2000). The Children's Sleep Habits Questionnaire (CSHQ): Psychometric properties of a survey instrument for school-aged children. Sleep, 23, 1043-1052.

Papageorgiou, K. A., \& Ronald, A. (2013). 'He who sees things grow from the beginning will have the finest view of them': A systematic review of genetic studies on psychological traits in infancy. Neuroscience and Biobehavioral Reviews, 37, 1500-1517.

Papageorgiou, K. A., \& Ronald, A. (2017). The genetic basis of psychological traits in infancy. In The Wiley handbook of developmental psychopathology (pp. 233-258). Wiley Blackwell.
Petrill, S. A., Saudino, K., Cherny, S. S., Emde, R. N., Fulker, D. W., Hewitt, J. K., \& Plomin, R. (1998). Exploring the genetic and environmental etiology of high general cognitive ability in fourteen-to thirty-six-month-old twins. Child Development, 69, 68-74.

Petrill, S. A., Saudino, K., Cherny, S. S., Emde, R. N., Hewitt, J. K., Fulker, D. W., \& Plomin, R. (1997). Exploring the genetic etiology of low general cognitive ability from 14 to 36 months. Developmental Psychology, 33, 544.

Pijl, M. K. J., Bontinck, C., Rommelse, N. N. J., Begum Ali, J., Cauvet, E., Niedzwiecka, A., Falck-Ytter, T., Jones, E. J. H., Van den Boomen, C., Bölte, S., Johnson, M. H., Charman, T., Warreyn, P., Roeyers, H., Buitelaar, J. K., Oosterling, I. J., \& EuroSibs Team. (2021). Parent-child interaction during the first year of life in infants at elevated likelihood of autism spectrum disorder. Infant Behavior and Development, 62, 101521.

Planalp, E. M., \& Goldsmith, H. H. (2020). Observed profiles of infant temperament: Stability, heritability, and associations with parenting. Child Development, 91 e563-e580.

Plomin, R., Emde, R. N., Braungart, J. M., Campos, J., Corley, R., Fulker, D. W., Kagan, J., Reznick, J. S., Robinson, J., Zahn-Waxler, C., \& Defries, J. C. (1993). Genetic change and continuity from 14 to 20 months: The Macarthur Longitudinal Twin Study. Child Development, 64, 1354-1376.

Pohl, A., Jones, W. R., Marrus, N., Zhang, Y., Klin, A., \& Constantino, J. N. (2019). Behavioral predictors of autism recurrence are genetically independent and influence social reciprocity: evidence that polygenic ASD risk is mediated by separable elements of developmental liability. Translational Psychiatry, 9, 1-9.

Polderman, T. J., Benyamin, B., De Leeuw, C. A., Sullivan, P. F., Van Bochoven, A., Visscher, P. M., \& Posthuma, D. (2015). Meta-analysis of the heritability of human traits based on fifty years of twin studies. Nature Genetics, 47, 702-709.

Price, T. S., Simonoff, E., Waldman, I., Asherson, P., \& Plomin, R. (2001). Hyperactivity in preschool children is highly heritable. Journal of the American Academy of Child and Adolescent Psychiatry, 40, 1362-1364.

Putnam, S. P., Gartstein, M. A., \& Rothbart, M. K. (2006). Measurement of fine-grained aspects of toddler temperament: The Early Childhood Behavior Questionnaire. Infant Behavior and Development, 29, 386-401.

Ripke, S., Walters, J. T., O’Donovan, M. C., \& Schizophrenia Working Group of the Psychiatric Genomics Consortium. (2020). Mapping genomic loci prioritises genes and implicates synaptic biology in schizophrenia. MedRxiv.

Robinson, B. F. (1999). Genetic and environmental influences on nonverbal and language abilities at 18 and 24 months of age (Unpublished doctoral dissertation). Emory University.

Roisman, G. I., \& Fraley, R. C. (2008). A behavior-genetic study of parenting quality, infant attachment security, and their covariation in a nationally representative sample. Developmental Psychology, 44, 831-839.

Ronald, A., Edelson, L. R., Asherson, P., \& Saudino, K. J. (2010). Exploring the relationship between autistic-like traits and ADHD behaviors in early childhood: Findings from a community twin study of 2-year-olds. Journal Of Abnormal Child Psychology, 38, 185-196.

Rothbart, M. K. (1981). Measurement of temperament in infancy. Child Development, 52, 569-578.

Sadeghi, N., Gilmore, J. H., \& Gerig, G. (2017). Twin-singleton developmental study of brain white matter anatomy. Human Brain Mapping, 38 1009-1024.

Sadeh, A., Mindell, J. A., Luedtke, K., \& Wiegand, B. (2009). Sleep and sleep ecology in the first 3 years: A web-based study. Journal of Sleep Research, 18, 60-73.

Saudino, K. J. (2005). Behavioral genetics and child temperament. Journal of Developmental and Behavioral Pediatrics, 26, 214-223.

Savage, J. E., Jansen, P. R., Stringer, S., Watanabe, K., Bryois, J., De Leeuw, C. A., Nagel, M., Awasthi, S., Barr, P. B., Coleman, J. R. I., Grasby, K. L., Hammerschlag, A. R., Kaminski, J. A., Karlsson, R., Krapohl, E., Lam, M., Nygaard, M., Reynolds, C. A., Trampush, J. W., .. Posthuma, D. (2018). Genome-wide association meta-analysis in 269,867 individuals identifies new genetic and functional links to intelligence. Nature Genetics, 50, 912-919.

Schröder, E., Gredebäck, G., Gunnarsson, J., \& Lindskog, M. (2020). Play enhances visual form perception in infancy-an active training study. Developmental Science, 23, e12923. 
Shakeshaft, N. G., \& Plomin, R. (2015). Genetic specificity of face recognition. Proceedings of the National Academy of Sciences, 112, 12887-12892.

Shakoor, S., Zavos, H. M., Haworth, C. M., McGuire, P., Cardno, A. G., Freeman, D., \& Ronald, A. (2016). Association between stressful life events and psychotic experiences in adolescence: evidence for gene-environment correlations. The British Journal of Psychiatry, 208, 532-538.

Sparrow, S. S., Cicchetti, D. V., \& Balla, D. A. (2005). Vineland Adaptive Behavior Scales, Second Edition, Survey Interview Form/Caregiver Rating Form. Pearson Assessment.

Stahl, E. A., Breen, G., Forstner, A. J., McQuillin, A., Ripke, S., Trubetskoy, V., Mattheisen, M., Wang, Y., Coleman, J. R. I., Gaspar, H. A., de Leeuw, C. A., Steinberg, S., Pavlides, J. M. W., Trzaskowski, M., Byrne, E. M., Pers, T. H., Holmans, P. A., Richards, A. L., Abbott, L., ... Bipolar Disorder Working Group of the Psychiatric Genomics Consortium. (2019). Genome-wide association study identifies 30 loci associated with bipolar disorder. Nature Genetics, 51, 793-803.

Stilp, R. L., Gernsbacher, M. A., Schweigert, E. K., Arneson, C. L., \& Goldsmith, H. H. (2010). Genetic variance for autism screening items in an unselected sample of toddler-age twins. Journal of the American Academy of Child and Adolescent Psychiatry, 49, 267-276.

Taylor, M. J., Rosenqvist, M. A., Larsson, H., Gillberg, C., D’Onofrio, B. M., Lichtenstein, P., \& Lundström, S. (2020). Etiology of autism spectrum disorders and autistic traits over time. JAMA Psychiatry, 77, 936-943.

Touchette, E., Dionne, G., Forget-Dubois, N., Petit, D., Pérusse, D., Falissard, B., Tremblay, R. E., Boivin, M., \& Montplaisir, J. Y. (2013). Genetic and environmental influences on daytime and nighttime sleep duration in early childhood. Pediatrics, 131, e1874-e1880.

Turkheimer, E., Haley, A., Waldron, M., d'Onofrio, B., \& Gottesman, I. I. (2003). Socioeconomic status modifies heritability of IQ in young children. Psychological Science, 14, 623-628.
UNESCO Institute for Statistics. (2012). International Standard Classification of Education: ISCED 2011. http://uis.unesco.org/sites/default/files/documents/ international-standard-classification-of-education-isced-2011-en.pdf

van Baal, G., De Geus, E., \& Boomsma, D. (1996). Genetic architecture of EEG power spectra in early life. Electroencephalography and Clinical Neurophysiology, 98 502-514.

van Hulle, C. A., Goldsmith, H., \& Lemery, K. S. (2004). Genetic, environmental, and gender effects on individual differences in toddler expressive language. Journal of Speech, Language, and Hearing Research, 47, 904-912.

van Leeuwen, E. M., Kanterakis, A., Deelen, P., Kattenberg, M. V., Slagboom, P. E., De Bakker, P. I., Wijmenga, C., Swertz, M. A., Boomsma, D. I., van Duijn, C. M., Karssen, L. C., \& Hottenga, J. J. (2015). Population-specific genotype imputations using minimac or IMPUTE2. Nature Protocols, 10, 1285-1296

Waddington, C. H. (2014). The strategy of the genes. Routledge.

Wetherby, A. M., Woods, J., Allen, L., Cleary, J., Dickinson, H., \& Lord, C. (2004). Early indicators of autism spectrum disorders in the second year of life. Journal of Autism and Developmental Disorders, 34, 473-493.

Yengo, L., Sidorenko, J., Kemper, K. E., Zheng, Z., Wood, A. R., Weedon, M. N., Frayling, T. M., Hirschhorn, J., Yang, J., Visscher, P. M., \& GIANT Consortium. (2018). Meta-analysis of genome-wide association studies for height and body mass index in $~ 700000$ individuals of European ancestry. Human Molecular Genetics, 27, 3641-3649.

Zagai, U., Lichtenstein, P., Pedersen, N. L., \& Magnusson, P. K. (2019). The Swedish twin registry: Content and management as a research infrastructure. Twin Research and Human Genetics, 22, 672-680.

Zietsch, B. P., Hansen, J. L., Hansell, N. K., Geffen, G. M., Martin, N. G., \& Wright, M. J. (2007). Common and specific genetic influences on EEG power bands delta, theta, alpha, and beta. Biological Psychology, 75, 154-164. 